\title{
Uncovering the complex role of private health insurance in Ireland
}

\author{
BRIAN TURNER AND SAMANTHA SMITH
}

The role of private health insurance in the Irish health system can be assessed from different angles and from all angles it appears complex. Despite universal entitlement to public hospital services, private cover - predominantly for hospital services - is purchased by nearly half of the population. This high level of demand has remained buoyant over time in the face of premium increases, adverse economic conditions, reductions in public subsidies and controversy within the market. Also, while private health insurance accounts for less than $15 \%$ of total spending on health, it commands a high profile in media and policy discussions and has substantial leverage over how public and private resources are allocated within the health system, particularly in the acute care sector.

This chapter analyses the structure and development of the market for private health insurance in Ireland and considers its impact on the wider health system. The market's development has been complicated, involving a series of high-level Irish and European court cases, highly visible exits from the market and other structural changes. In addition, its role has changed over time, as entitlements to publicly financed health care have also changed. However, one of the most distinctive aspects of the Irish experience comes from the complex interaction between publicly and privately financed health care and the impact of private health insurance on the distribution of resources in the wider health system. The chapter unpicks these complexities, highlighting critical issues around equity and efficiency.

\section{The Irish health system}

\section{Overview of financing}

The Irish health system is financed by a mix of public and private resources. Public resources have consistently accounted for the largest 
share (approximately 66\% in 2014) of total spending on health, mainly funded from the government budget. Private spending includes direct outof-pocket payments by households ( $50 \%$ of private spending and $15 \%$ of all current spending on health) and claims expenditure (41\% and $12 \%$, respectively) by private insurers on behalf of their members (WHO, 2018). The share of health spending coming from private sources has increased in recent years, from $21 \%$ in 2008 to $31 \%$ in 2014 (Turner, 2016). ${ }^{1}$

\section{Access to Irish health care services}

There are two broad categories of eligibility to public health care services, with each group facing different sets of prices for health care:

\section{- Category I ("Full” Medical Card holders)}

Category I beneficiaries [nearly 1.74 million people or $38 \%$ of the population in 2015 (HSE, 2016)] are granted a Medical Card (labelled here as a "full Medical Card" for clarity). Full Medical Card holders (individuals and dependants) have access to the following services that are free at the point of use: general practitioner (GP) care, approved prescribed drugs and medicines, ${ }^{2}$ inpatient and day-case treatment in public beds in public hospitals, outpatient services in public hospitals, medical and midwifery care for mothers and infants, maternity cash grant for each child born, and dental, ophthalmic and aural services and some personal and social care services (for example, public health nursing, social work services, other community services) (Expert Panel on Medical Need for Medical Card Eligibility, 2014; HSE, 2015a).

${ }^{1}$ It should be noted that comparisons of health care financing data between Ireland and other countries remain problematic given the challenges in distinguishing between social and health care spending in the Irish context and it is acknowledged that health care has been over-stated to some degree in Irish expenditure data (www.cso.ie/en/releasesandpublications/er/sha/ systemofhealthaccounts2014/ last accessed 23/12/2016).

2 Prescription charges are now levied (€2.50 per item dispensed, subject to a maximum of $€ 25$ a month for an individual or a family) (Expert Panel on Medical Need for Medical Card Eligibility, 2014). However, it was announced in Budget 2016 that these charges will be reduced in 2017 to $€ 2.00$ per item subject to a maximum of $€ 20$ per month for those aged over 70 in possession of medical cards. 
As outlined by the Health Service Executive (HSE, 2015b) the three main groups of people entitled to a full Medical Card include:

- Applicants (and their dependants) whose assessable income comes within a set of income guidelines. ${ }^{3}$ The majority of full Medical Cards are granted on the basis of this means test, which takes into account both income and allowances for specified living expenses (for example, childcare costs) so that an individual's overall financial situation is assessed (Expert Panel on Medical Need for Medical Card Eligibility, 2014). ${ }^{4}$

- Applicants (and their dependants) whose assessable income exceeds the income guidelines but where it is considered that refusal of a Medical Card would cause "undue hardship" (HSE, 2015b: p.6).

- Applicants who are exempt from the means test including individuals with EU entitlement, ${ }^{5}$ individuals with retention entitlement under Government schemes (for example, retention of Medical Card for specified period after return to work), individuals affected by the drug Thalidomide, and survivors of symphysiotomy. ${ }^{6}$

Between 2001 and 2008, people aged 70 and over were automatically entitled to a full Medical Card, but automatic entitlement

${ }^{3}$ Applicants whose weekly incomes are derived solely from Social Welfare or Health Service Executive allowances are entitled to a Medical Card (HSE, 2015b).

${ }^{4}$ For individuals aged 70 and over, the means test is based on gross income at higher thresholds and expenditure is not taken into account but these individuals can also apply under the general medical card scheme (Expert Panel on Medical Need for Medical Card Eligibility, 2014).

${ }^{5}$ This applies to, among others, people receiving social security pension from another EU/EEA country or Switzerland, or working and paying social insurance in one of these countries, if they are ordinarily resident in Ireland. (www.citizensinformation.ie/en/health/medical_cards_and_gp_visit_cards/ medical_card.html).

${ }^{6}$ People who contracted Hepatitis C/HIV from the use of Human Immunoglobulin anti-D blood products qualify for a Health Amendment Act Card. This card entitles the holder to a range of services that are free at the point of use, including general practitioner care, prescribed drugs and medicines, home nursing and home help services, and others (HSE, 2015b). 
was replaced by means-tested eligibility in 2009 (to save money) (Government of Ireland, 2001, 2008).

\section{- Category II (Other)}

People in Category II are entitled to public hospital care, subject to inpatient and outpatient charges, and to maternity and infant services. ${ }^{7}$ They can apply for the Drugs Payment Scheme, which covers the cost of prescribed drugs, medicines and certain appliances above a threshold of $€ 144$ per month. ${ }^{8,9,10}$ However, for claimants under this scheme (less than $6 \%$ of the population in 2015 ), the state covered less than half of the total cost of medicines over the period 2011-2015 (PCRS, 2015). This is down from $63 \%$ in the period 2003-2007 (PCRS, 2007), and is indicative of a shifting of the burden of payment over that period, arising from increases in the monthly threshold.

Entitlements for individuals in Category II to community and social services (for example, public health nursing, home help, physiotherapy) are difficult to ascertain. The overall pattern of entitlement to community services has been described as "complex and confusing” (Ruane, 2010: p.45). In practice, access to community services can vary depending on availability in each area (Citizens Information, 2015a) and in some cases priority may

7 Inpatient charges are levied at $€ 75$ per night up to a maximum of $€ 750$ in any 12 consecutive months, and Emergency Department visits without referral letter are charged at $€ 100$ per visit, although certain exemptions apply. (www.hse.ie/eng/services/list/3/hospitals/Hospitalcharges.html last accessed 26/11/2015).

${ }^{8}$ www.hse.ie/eng/services/list/1/schemes/drugspaymentscheme/last accessed 26/11/2015.

9 Medicines prescribed to inpatients are covered under hospital costs.

10 Additional public assistance schemes include the Long-Term Illness Scheme, which covers the costs of prescription medicines, medical and surgical appliances directly related to the treatment of the illness for certain specified conditions (for example, diabetes). The High-Tech Drugs Scheme covers the cost of very expensive high-technology medicines that are usually only prescribed/initiated in hospital (for example, anti-rejection drugs for transplant patients or medicines used in conjunction with chemotherapy or growth hormones). 
be given to Medical Card holders. ${ }^{11}$ In particular, lack of clear eligibility criteria in home care (that is, home help, home care packages) has been criticized for giving rise to "uneven provision and hence glaring inequity in access to services throughout the country" (Timonen, Doyle \& O’Dwyer, 2012: p.316). Tax relief at the standard tax rate $(20 \%)$ is available for all medical expenses that are not otherwise reimbursed by public funding or by private health insurance (Nolan \& Smith, 2012).

Individuals in Category II who are not eligible for a GP Visit Card (see below) are required to pay privately for GP care (Citizens Information, 2015a) with the exception of maternity and infant GP services, which are provided free of charge for a specific number of visits (Nolan \& Smith, 2012). These services can be expensive, with the average charge for visiting a GP estimated to be $€ 52.50$ (Burke et al., 2015). There is no high-cost protection from the state (for example, no annual cap on out-of-pocket payments) for GP visits for individuals in Category II.

\section{- GP Visit Medical Card}

Over time, the above two categories have become more complicated with the introduction of the GP Visit Card. The GP Visit Card was introduced in 2005, granting access to GP visits free at the point of use. GP Visit Card holders fall under Category I for GP care, but under Category II for all other health care services.

Eligibility for a GP Visit Card is based on a means test whereby the income thresholds are approximately $50 \%$ higher than those set for the Full Medical Card (Expert Panel on Medical Need for Medical Card Eligibility, 2014). As with full Medical Cards, discretionary GP Visit Cards may be issued where the assessed means of the applicant exceed the income guidelines but the absence of the GP Visit Card would cause undue hardship.

However, since July 2015, all children under the age of 6 , and since August 2015, all individuals aged 70 and over, are granted

11 For example, access to physiotherapy in a primary care team in Dublin South is prioritized for Medical Card holders and for clients living in the catchment area of the health centre (www.hse.ie/eng/services/list/2/PrimaryCare/pcteams/ dublinsouthpcts/blackrockpct/physio.html last accessed 15/04/2016). 
a GP Visit Card regardless of means ${ }^{12,13}$ and there are long-term plans to roll out free at the point of use GP care to the rest of the population (Government of Ireland, 2014), although this is dependent on the successful negotiation of a new GP contract. In 2015 there were over 431000 people with a GP Visit Card (HSE, 2016).

Many people in Category II, and a small proportion of those in Category I, purchase supplementary private health insurance. Thus, the population can be categorized into four entitlement groups: full/ GP Visit Medical Card only with no supplementary insurance (30\%); privately insured only with no medical card $(41 \%)$; individuals with both medical card and private health insurance $(6 \%)$; individuals with neither medical card nor private health insurance $(23 \%)$ (CSO, 2011). Based on descriptive survey data, these entitlement groups can be broadly ranked in terms of socioeconomic status from the medical card only group (lowest) to the privately insured only group (highest), but overlaps in the various measures of deprivation and socioeconomic status suggest that these do not describe mutually exclusive socioeconomic categories (Smith \& Normand, 2009). The higher socioeconomic status of privately insured individuals has been a consistent feature of consumer surveys, with those in higher social classes more likely to have private health insurance than those in lower social classes (see, for example, HIA, 2016a). As discussed by Brick et al. (2010), given the links between low socioeconomic status, older age and poor health status, these patterns suggest poorer health status among the medical card groups (with and without private health insurance) relative to the non-medical card groups and there is survey evidence to support this.

\section{Health care delivery structures}

\section{Primary care delivery}

Primary care is delivered by GPs and other health professionals in the community including public health nurses, community registered nurses,

${ }^{12}$ www.hse.ie/eng/services/list/1/schemes/mc/gpvc/GPVisitCards.html last accessed 24/11/2015.

13 www.hse.ie/eng/services/list/1/schemes/mc/over70s/ last accessed 24/11/2015. 
physiotherapists, occupational therapists, and speech and language therapists. There is a also a range of other primary and social care services provided in a community setting including home help, day care and respite care. These services are provided by the HSE or by voluntary organizations operating in conjunction with, or on behalf of, the HSE (Citizens Information, 2015b). It is well-documented that there is a wide variation in the level of services available in different parts of the country (Citizens Information, 2015b).

General practitioners in Ireland are self-employed private practitioners, although a large proportion hold a state General Medical Services contract to provide GP care that is free at the point of use to Medical Card and GP Visit Card holders (HSE, 2015c). A small number of GPs who do not hold a General Medical Services contract are registered to provide services under alternative state-funded programmes (for example, Primary Childhood Immunization Scheme, Heartwatch, Methadone Treatment Scheme) (HSE, 2015c). GPs are mainly paid on a capitation basis for Medical Card and GP Visit Card patients and on a fee-for-service basis by non-Medical Card patients.

\section{Long-term care delivery}

Approximately $75 \%$ of non-acute long-term care beds are provided by private nursing homes (Health Information and Quality Authority, 2014), 20\% are provided by the HSE (mostly in extended care units, and a small number in welfare homes), and the remaining $5 \%$ are provided by non-statutory/voluntary agencies (for example, voluntary homes or hospitals for older people, and a small number of beds in voluntary welfare homes) (Health Information and Quality Authority, 2014).

\section{Acute care delivery}

Acute hospital services are delivered by public and private hospitals (Brick et al., 2010). Public hospitals are either owned and directly managed by the HSE, or owned by voluntary organizations but for many years have received most of their funding from the Government (Brick et al., 2010). There are 50 acute care public hospitals in the Republic of Ireland, managed by voluntary organizations or directly by the HSE (HSE, 2015d). In addition there are 19 independent hospitals (providing acute and mental health care services) registered with the Private 
Hospitals Association. ${ }^{14}$ Private hospitals operate in parallel with public hospitals, and some now offer limited emergency department services (for example, office hours only), ${ }^{15}$ but there are some complex treatments that are not available in the private sector (Brick et al., 2010).

Specialists (known as "consultants"), working in public hospitals are paid according to a common contract which was revised in 2008 and now includes a new public-only contract. Type A contracts are for public-only consultants who are not permitted to earn private income from the treatment of private patients. Type B contracts allow consultants to treat private patients in public hospitals. Type $\mathrm{C}$ contracts allow consultants to treat private patients outside the public hospital campus (that is, in private hospitals). Consultants are paid on a salary basis for treating public patients and can earn additional income on a fee-for-service basis when treating private patients.

\section{Public/private interaction in the Irish health care system}

Despite its relatively small financial contribution to total health care resources, private health insurance plays an important role in the health system. To understand its influence requires knowledge of the complex interactions between the public and private sectors within the system. In both primary and acute hospital care, publicly and privately financed care is very often administered by the same staff, using the same facilities. The main structural difference is in the method of reimbursement. Care for private patients is reimbursed on a fee-for-service basis whereas care for public patients is largely reimbursed on a fixed payment basis (for example, salary, capitation).

The overlap between public and private care in the public hospital system was, in the past, explicitly supported in government policy. It was defended in terms of permitting public hospitals to retain the services of top medical specialists and therefore to have them available to care for public patients. The 2001 national strategy for the Irish health care system stated that the public/private mix of beds in the public hospital

${ }^{14}$ http://privatehospitals.ie/members/ last accessed 26/11/2016.

${ }^{15}$ For example, the Emergency Department at the Beacon Hospital in Dublin is open 10am to $7 \mathrm{pm}$ Monday to Friday, 10am to 6pm Saturdays, closed Sundays and Bank Holidays (www.beaconhospital.ie/emergency-department/ last accessed 23/11/2015). 
system was intentional, to ensure that the two sectors could share resources, clinical knowledge, skills and technology (DoHC, 2001). However, the overlap also gave rise to complicated incentive patterns and concerns about equity within the system, discussed in more detail below.

Government policy on this overlap of public and private care in hospitals has since shifted. For example, private bed charges are now levied on the use of any bed in public hospitals by privately insured patients from 1 January 2014 (previously, only those accommodated in designated private beds were charged), and tax relief on private health insurance premiums has been capped (Turner, 2015).

These changes reflect a broader shift in government health care policy aimed at reforming the delivery and financing of the health care system (DOH, 2012). In particular, a White Paper outlining a plan to introduce a system of universal health insurance with mandatory coverage of the whole population provided by competing private insurers was produced in 2014 (DOH, 2014). Under these proposals, the goal was to develop a single-tier health service that promotes equitable access to health care. For example, private health insurers would no longer be able to offer faster access to hospital care, but would still be able to provide better amenities in hospital. However, there is debate as to what would be the most efficient financing mechanism to achieve the reform goals. For example, analysis by Wren, Connolly \& Cunningham (2015) indicated that the costs of the chosen model of a multi-payer universal health system could be significant, and there is need to examine alternative mechanisms. Plans to introduce the proposed model have been shelved for now and the Government elected in 2016 established a cross-party parliamentary Committee on the Future of Healthcare tasked with recommending a consensus approach to the future direction of health policy in Ireland over the next 10 years. ${ }^{16}$ Part of the Committee's remit is to work towards a universal single-tier health system where access is based on need rather than ability to pay.

\section{Overview of the market for private health insurance}

\section{Market structure}

Four insurers currently operate in the unrestricted market for private health insurance: a non-profit insurer, Vhi Healthcare, and three

${ }^{16}$ For full details of the Committee, including its role, see www.oireachtas.ie/ parliament/oireachtasbusiness/committees_list/future-of-healthcare/. 
for-profit (commercial) insurers, Laya Healthcare, Irish Life Health and GloHealth. Seven undertakings restrict membership to specific (mostly vocational) groups and they therefore do not compete to any great extent with the other insurers (HIA, 2016b). The largest of these are operated by, or on behalf of, the Irish police force, the country's prison officers and employees of the state-owned Electricity Supply Board. Recent figures suggest that Vhi Healthcare has a $51 \%$ market share, Laya Healthcare a $26 \%$ share, AVIVA Health (now Irish Life Health) $14 \%$ and GloHealth 5\%, with the remaining $4 \%$ accounted for by the restricted membership undertakings (HIA, 2016c).

Hospital plans account for the vast majority of private health insurance and provide access to semi-private ${ }^{17}$ or private rooms in public hospitals, ${ }^{18}$ and access to private hospitals (in a semi-private or private room) depending on the level of cover. Most hospital plans provide limited cover for ancillary (non-hospital) services, such as visits to GPs, physiotherapists, dentists and other health care practitioners. However, in recent years, an increasing number of hospital plans with significant ancillary cover have been introduced. Ancillary plans have also been introduced, some of which may be purchased on a stand-alone basis, whereas others can be combined with hospital plans. The ancillary plans are primarily complementary, while the hospital plans (the ones with limited ancillary cover) are primarily supplementary. The combined hospital and ancillary plans are both complementary and supplementary.

A concern expressed about private health insurance markets in general is that product differentiation can restrict competition if consumers find it difficult to compare price and quality across a wide range of products (see, for example, Thomson \& Mossialos, 2007). This is of relevance in the Irish context given the increase in the number of plans available in recent years. The Health Insurance Authority (HIA) has commissioned a number of surveys to assess consumer behaviour and

${ }^{17}$ A semi-private room may contain up to five beds.

${ }_{18}$ As mentioned above, there was a change to bed designation in public acute hospitals on 1 January 2014. Insured patients are now charged the private bed rate for the use of any bed in a public hospital. Previously, privately insured patients occupying designated private beds were charged the private bed rate but private patients occupying public or non-designated beds were only charged the statutory bed rate (currently $€ 75$ per night up to a 12 -month maximum of $€ 750)$. This is despite the fact that consultants were being paid for seeing all of these insured patients as private patients. It should also be noted that private or semi-private accommodation was subject to availability. 
attitudes towards the market. The first survey (HIA, 2003a) showed that only $30 \%$ of consumers had a full understanding of the cover provided by their plan. As a result of evidence that consumers had difficulty understanding the cover provided by different plans, the HIA engaged in an information campaign, publishing a guide on consumers' rights in relation to health insurance, a guide to switching plans and a comparison table outlining the key elements of cover offered by the main plans available in the market. Recent survey evidence (HIA, 2016a) shows a large majority of consumers $(85 \%)$ being satisfied or very satisfied with their level of understanding of their cover. However, only a third of all consumers $(34 \%)$ felt that there was adequate information available to compare plans from different insurers, compared with $46 \%$ in 2009 (HIA, 2016a). This may be related to the increasing number of plans available in the market, with 360 plans available at the end of 2015 (HIA, 2016b).

Although insurers are not obliged to contract with all providers, in practice all insurers cover most public and private hospitals and have fully participating agreements with most consultants, although some lower-cost plans in recent years have restricted the number of hospitals covered. Consultants who have signed up to these agreements accept the insurers' payments in full and do not balance-bill the customers of those insurers. Claims account for the majority of insurers' costs, and these have been rising in recent years. Reasons include advances in medical technology, the ageing population and increases in the charges for private beds in public hospitals, an issue to which we shall return (see, for example, Turner, 2013).

In the last two decades, inflation in the health insurance element of the consumer price index (CPI) has tended to exceed inflation in the CPI's Health category which, in turn, has tended to exceed the overall level of inflation. Figures from the Central Statistics Office show that, between January 1997 (when BUPA Ireland began selling plans) and September 2016, the overall CPI increased by $49 \%$, while the Health category of the index rose by $120 \%$ and the health insurance sub-index rose by $520 \%$ (source: Central Statistics Office database, available at www.cso.ie).

\section{Demand for private health insurance}

The initial aim of private health insurance (in the 1950s) was to provide cover for the wealthiest proportion of the population (approximately 
$15 \%)$, who, at the time, were required to pay inpatient bed charges, consultant treatment costs for inpatient care and outpatient charges in public hospitals. Demand was buoyant and the share of the population covered grew from 4\% in 1960 to $35 \%$ by 1987 and further to a peak in late 2008 of almost $51 \%$, before falling back during the economic crisis, and now stands at 46\% (Nolan, 2004; HIA, 2016d). Total premium income in the open (unrestricted) market in 2015 was just over €2.33 billion (HIA, 2016c). This increase in the popularity of private health insurance is not fully understood. Growth occurred in spite of substantial increases in premiums, a reduction in tax relief on premiums ${ }^{19}$ and enhanced access to publicly financed health care (eligibility for public hospital accommodation was extended to all Irish residents in 1979 and for treatment by public hospital consultants in 1991).

Econometric analysis has indicated that a large part of the increase in demand remains unexplained, even after controlling for income and price changes (Nolan, 2004). Attention has turned to attitudinal surveys, particularly those commissioned by the HIA (see, for example, HIA, 2016a). Figure 7.1 shows the level of agreement with a number of statements among HIA survey respondents (both with and without health insurance). Overall majorities of consumers in these surveys agreed that private health insurance is a necessity rather than a luxury. ${ }^{20}$ There was also broad agreement that having private health insurance enables people to access better health care services and allows faster access. Most consumers disagreed with a statement suggesting that there is no need for private health insurance in Ireland because public services are adequate. These findings mirror those of earlier studies (Nolan \& Wiley, 2000; Harmon \& Nolan, 2001; Nolan, 2004), which found

19 Tax relief was granted on private health insurance premiums from the time the market was established. The relief was originally available at the individual's marginal tax rate, but reduced to the standard rate (currently $20 \%$ ) over two tax years in the mid-1990s, to make it less regressive. Since 2001 tax relief has been deducted at source. The insurer deducts the tax relief from the premium charged to the individual before the premium is paid. Tax relief operates more as a tax credit and is available to anyone whether or not they are a taxpayer (DoHC, 2005). However, in October 2013, the premium subject to tax relief was capped at $€ 1000$ per adult and $€ 500$ per child (Turner, 2015).

${ }^{20}$ Although a minority of those without insurance agreed with this statement in the most recent survey, it was nonetheless a sizeable minority). 


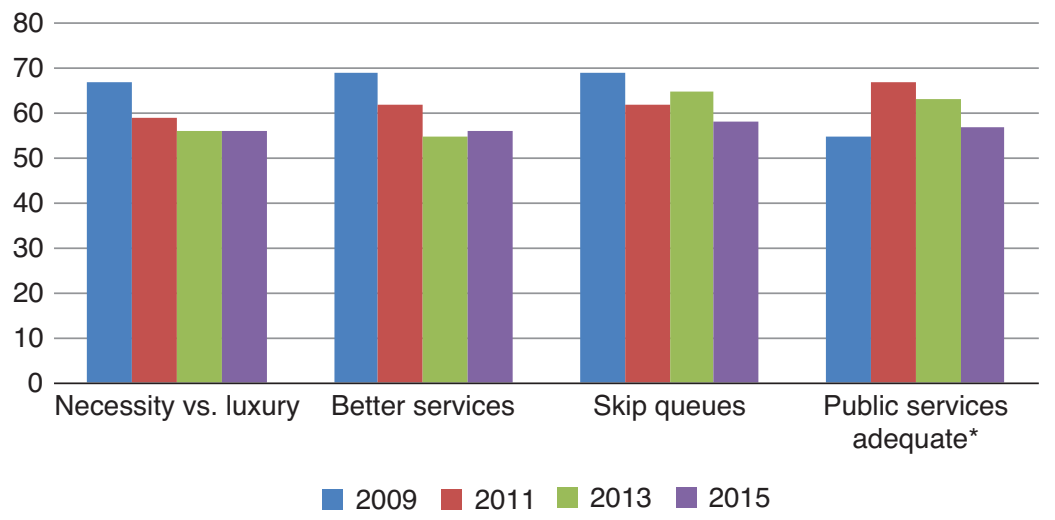

Figure 7.1 Consumer attitudes to private health insurance in Ireland, 2009-2015 (selected years)

Sources: HIA (2010a, 2012, 2014, 2016a).

Note: * Percentage disagreeing.

that perceptions of greater access to hospitals and greater quality of private versus public care were the key drivers underpinning demand for health insurance with other reasons including ensuring good treatment, receiving direct consultant care and avoiding large hospital bills (Nolan \& Wiley, 2000).

\section{Market development and public policy}

\section{Government objectives}

As discussed above, private health insurance has previously been actively supported by the government. The 2001 national health strategy described it as a "strong complement to the publicly funded system" and a vital part of the "overall resourcing of health care in this country" (DoHC, 2001: p.111). As well as providing additional resources, the market was expected to relieve the publicly financed system of demand for care. Tax relief on premiums was justified on the basis "that those who opt for private cover effectively forgo a statutory entitlement while continuing to contribute to the funding of the public health service through taxation" (DoHC, 1999: p.24). However, as noted earlier, more recent government policies have been aimed at unwinding the State subsidy of private health insurance (Turner, 2015) and increasing 
equity in the Irish health system, although plans for universal health insurance are currently in abeyance.

Objectives for the market have changed over time. Initially, it was envisaged that private health insurance would play a substitutive role for the top $15 \%$ of earners in the country (those who were not entitled to free care in public hospitals). However, enrolment was not limited to this group. For some, private health insurance offered the option of better accommodation or choice of consultant, while it gave the option of treatment in private hospitals to many subscribers, irrespective of their entitlements to public hospital treatment. Therefore, it also played a supplementary role, even in the early days of the market. However, since entitlements to publicly financed health care were extended in 1979 and 1991, private health insurance no longer plays a substitutive role. It now plays primarily a supplementary role, with elements of a complementary system.

\section{Legislative background}

The market in its current form was established in 1957 with the passing of the Voluntary Health Insurance Act, 1957, which set up the Voluntary Health Insurance Board (VHI, now trading as Vhi Healthcare) as a statutory body. The Minister for Health at the time was advised that such a scheme would have a wider appeal to the public if administered by a non-profit company rather than a state department (O'Morain, 2007). Before 1957, there had been a number of attempts to establish private health insurance, but none of these was successful for a variety of reasons, including a lack of public interest, the cost of meeting claims for pre-existing conditions and large premium increases (see O'Morain, 2007 for further details).

In 1992, the introduction of the European Third Non-Life Insurance Directive $^{21}$ required European Union (EU) Member States to open their non-life insurance markets to competition. The Directive was reflected in the Irish Health Insurance Act 1994 which, with associated regulations brought forward in 1996, gave legislative foundation to a number of principles that private health insurance had adhered to on a de facto basis. In particular, the 1994 Act enshrined in legislation what have become known as the three "pillars" of the Irish market: community

21 Council Directive 92/49/EEC of 18 June 1992. 
rating, open enrolment and lifetime cover. The 1999 White Paper on private health insurance states that these three principles "have played a crucial role in making private health insurance cover accessible to a substantial proportion of the Irish population and, in particular, to higher risk groups such as the elderly and the chronically ill" (DoHC, 1999: p.8).

Community rating prohibits insurers from varying premiums or benefits between individuals with the same health insurance contract, subject to some exceptions..$^{22}$ Until 2015, this was operated under a system of single-rate community rating, meaning that a person's age at entry did not affect the premium they paid. However, from 1 May 2015, lifetime community rating has operated in the market. Open enrolment requires insurers to accept any applicant, ${ }^{23,24}$ although insurers may impose waiting periods, which are age-related. Three types of waiting periods are permitted - an initial waiting period (for a first-time applicant or an applicant who has had a break in cover of 13 weeks or more), one for pre-existing conditions and one for upgrades in cover. The maximum permitted waiting periods for each of these categories, before 1 May 2015, are outlined in Table 7.1. Since that date, the maximum waiting periods have been standardized at the lowest level, that is, 26 weeks for the initial waiting period (except for maternity benefits, for which the waiting period is still 52 weeks), 5 years for the pre-existing condition waiting period and 2 years for the upgrade in cover waiting period. Even during the initial waiting period, however, insured people are eligible for minimum payments for health services provided as a result of

22 The exceptions were children under the age of 18 and full-time dependent students aged 18-23, for whom premiums may be reduced such that any reduced premium was no greater than $50 \%$ of the adult premium; and members of a group scheme, for whom premiums may be reduced by up to $10 \%$. However, premiums may not be varied among insured people falling into these categories. Since $1^{\text {st }}$ May 2015, premiums may still be reduced for children and members of group schemes, but the student discount has been replaced by a discount for young adults, aged between 18 and 25 inclusive, on a sliding scale.

${ }^{23}$ Unless the person has committed fraud that caused, or could have caused, financial loss to an insurer.

${ }^{24}$ The original regulations from 1996 specified that this applied only to those aged under 65 when first applying for health insurance, or applying after a break in cover of thirteen weeks or more, but this stipulation was removed in 2005 . 
Table 7.1 Maximum permitted waiting periods for private health insurance benefits in Ireland before 2015

\begin{tabular}{lllll}
\hline Age (years) & Under 55 & $55-59$ & $60-64$ & 65 plus \\
Initial waiting period & 26 weeks & 52 weeks & 52 weeks & 104 weeks \\
Pre-existing condition & 5 years & 7 years & 10 years & 10 years \\
Upgrade in cover & 2 years & 2 years & 2 years & 5 years \\
\hline
\end{tabular}

Source: Health Insurance Act 2001; (Open Enrolment) Regulations 2005.

Note: Maternity benefits are not covered for the first 52 weeks.

accident or injury. During the waiting period for an upgrade in cover, insured people will still be covered at the lower level of cover, subject to any initial or pre-existing condition waiting periods that they may be serving. Lifetime cover means insurers may not refuse to renew cover for any insured person. ${ }^{25}$

In addition to these three pillars, regulations introduced in 1996 specified a set of minimum benefits that any eligible health insurance contract must provide. The regulations were designed "to ensure that individuals do not significantly under-insure due to lack of proper understanding of the restrictions which, in the absence of a specified minimum entitlement, could apply to some types of policies" (DoHC, 1999: p.54). Monetary amounts specified in these regulations were not inflation-linked and are now significantly out of date, given the rate of medical inflation. In practice, however, cover provided by all insurers is significantly greater than the minimum required under the regulations.

The same regulations specified a risk equalization scheme to "equitably neutralize differences in insurers' claim costs that arise due to variations in the health status of their members" (HIA, 2010b: p.8) by transferring money from insurers with relatively low-risk membership profiles to a risk equalization fund, from which money is received by insurers with relatively high-risk membership profiles. These regulations were revoked in 1999 during a period of consultation on the future of private health insurance, which led to the publication of the White Paper (DoHC, 1999). In 2001, the Health Insurance (Amendment) Act allowed

${ }^{25}$ Unless the person has committed fraud or the insurer ceases to carry on health insurance business in the country. 
the Minister for Health and Children to specify a new risk equalization scheme, introduced in 2003. It also established a new independent statutory body, the HIA, to regulate the private health insurance market. ${ }^{26}$ The HIA's role was initially primarily one of monitoring and advising the Minister for Health and Children, and it did not have widespread powers to impose sanctions on insurers in the event of noncompliance with legislation. The Health Insurance (Miscellaneous Provisions) Act, 2009 gave it greater powers of enforcement.

\section{Development of competition}

For 40 years from its establishment in 1957, Vhi Healthcare had a monopoly position in the market. Since the passing of the 1994 Act (to comply with EU law) there have been a number of entries into the market and changes of ownership of these new entrants.

- The first entrant into the market was the British United Provident Association (BUPA), which set up BUPA Ireland in 1996. Following an unsuccessful challenge against the Risk Equalization Scheme, 2003 in the Irish High Court, BUPA Ireland announced its withdrawal from the market in December 2006. BUPA Ireland's business was subsequently acquired by Quinn Insurance Limited, which already sold other forms of non-life insurance in Ireland, and was re-branded Quinn Healthcare in April 2007. After a management-led buyout in 2012 the company was renamed Laya Healthcare.

- VIVAS Health was established in 2004 and was the third provider in the market. In early 2008, Hibernian Insurance Limited, part of the AVIVA group, which already sold both life and non-life insurance in Ireland, acquired a majority stake in VIVAS Health, which was subsequently re-branded as AVIVA Health. In 2016, Irish Life acquired AVIVA Health, which has now been renamed Irish Life Health.

- GloHealth was established in 2012. In 2016, as well as acquiring AVIVA Health, Irish Life also acquired the stake in GloHealth that

${ }^{26}$ Before the establishment of the HIA, the Department of Health and Children regulated the market. The HIA can be regarded as the regulator for the market, whereas the Department of Health and Children is the legislator for the market. 
it did not already own, although GloHealth has so far been maintained as a separate brand.

The relatively low number of insurers has been an issue of concern since the market opened up to competition. An early report on competition and risk equalization commissioned by the HIA and carried out by the York Health Economics Consortium identified the prospect of risk equalization and the status of Vhi Healthcare as a state-backed dominant player, combined with uncertainty at the time over its future status, as key factors contributing to the low level of existing competition and limited scope for future competition (York Health Economics Consortium, 2003). The report suggested that, even if risk equalization payments were implemented, the Irish market would still be likely to attract some new entrants, but fewer than if payments were not implemented. The report also concluded that, in the absence of risk equalization, the benefits to consumers of new entrants might be limited, as "lower prices and higher profits for insurers could be achieved for some but older people with health insurance, less inclined to move between insurers, would lose from the absence of full risk equalization" (York Health Economics Consortium, 2003: p.97).

Evidence from HIA surveys indicates that, by late 2002, only $6 \%$ of respondents who had health insurance had ever switched health insurer. This increased to $10 \%$ by 2005 , levelled off by 2007 , increased to $16 \%$ in 2009 and $23 \%$ in 2011, before dropping back to $20 \%$ in 2013 and increasing again to $24 \%$ in 2015 (HIA, 2016a). The main reason for switching is to achieve cost savings, while the main reason for nonswitching is satisfaction with current insurer. Most of the surveys also show that fewer than one in seven of those who have not switched have seriously considered switching, although this figure increased to $20 \%$ in 2013 and 2015 (HIA, 2016a). Furthermore, recent evidence suggests that switching and price sensitivity are lower among older consumers (Keegan et al., 2016).

These findings suggest that competition among insurers is primarily for first-time purchasers of health insurance, who tend to be younger than the average age of existing consumers, which would work to the disadvantage of Vhi Healthcare, as the longest-established insurer in the market. They are consistent with the idea of adverse retention: the tendency for people who do not switch plans to magnify cost differentials between plans (Altman, Cutler \& Zeckhauser, 1998). One of the 
factors that Altman, Cutler \& Zeckhauser (1998) suggested will affect the extent of adverse retention is the length of time for which the plans have been offered; in other words, if people do not switch plans to any great extent, adverse retention will drive up the costs of older plans relative to newer ones. Price \& Mays (1985) also suggested that older plans may have an older mix of consumers.

Another issue relevant to competition in the market is risk selection, whereby insurers attempt to cherry-pick low-risk individuals in order to reduce claim costs and increase profits. Community rating accentuates incentives to risk select, and while open enrolment and lifetime cover reduce the opportunities for cherry-picking, they do not eliminate them, as risk selection may occur in subtle forms, such as marketing or plan design - as noted by York Health Economics Consortium (2003), among others. While the effects of adverse retention and risk selection are difficult to disentangle, Turner \& Shinnick (2008) find evidence suggesting that risk selection might be present in the Irish market, while Keegan et al. (2017) find that incentives to engage in risk selection may exist even in the face of a risk equalization scheme.

Following BUPA Ireland's withdrawal from the market, the Minister for Health and Children requested the HIA and the Competition Authority to report on competition in the market. Both reports (Competition Authority, 2007; HIA, 2007) recommended the normalization of Vhi Healthcare's regulatory position (see below), an increase in the powers available to the HIA, measures to facilitate switching by consumers (including the implementation of a switching code and the provision of information to consumers at the point of sale and with renewal notices), and updating of the minimum benefit regulations. Similar recommendations were made in a third report commissioned by the Minister (Private Health Insurance Advisory Group, 2007). This report led to a number of policy changes by government, including the reduction of risk equalization payments by $20 \%$ (although this was never realized - the Risk Equalization Scheme, 2003 was set aside by the Supreme Court before payments were made under the Scheme; see below).

\section{Sources of controversy}

Developments in the private health insurance market have attracted much media and political attention in recent years, particularly in 
relation to the introduction of risk equalization. The issues are not straightforward and much of the discussion is confused with wider complications around the role played by private health insurance in the health system. Here, we discuss key sources of controversy around the structure of the private health insurance market in some detail to clarify issues that have been confused in popular debate. The complications arising from the interaction between public and private care are discussed separately in subsequent sections.

\section{Prudential regulation}

In addition to the regulation of health insurance business, health insurers must comply with prudential regulatory requirements. This has been a source of controversy due to a different prudential regulatory regimen being applied to Vhi Healthcare from that applying to its competitors. Under the 1957 Act, Vhi Healthcare was not subject to the Insurance Acts in Ireland, and it also received a derogation from the EU's First Non-Life Insurance Directive. In particular, it was not required to maintain the same level of solvency reserves as its competitors. However, in contrast to its competitors, Vhi Healthcare has to seek ministerial approval for premium increases.

Before BUPA Ireland's withdrawal from the market, all three insurers at the time had different prudential regulatory accountability. Vhi Healthcare, as a statutory body, reported to the Minister for Health and Children; BUPA Ireland, as a subsidiary of BUPA Insurance Limited, was regulated by the Financial Services Authority in the United Kingdom, while VIVAS Health was regulated by the Financial Regulator (responsible for regulating all financial services firms in Ireland). The different prudential regimen applied to Vhi Healthcare attracted opposition from its competitors. Following a formal complaint from VIVAS Health, the European Commission (EC) deemed that Vhi Healthcare's derogation from solvency requirements should be removed. Legislation was drafted to normalize Vhi Healthcare's status, but not implemented, and in 2011 the European Court of Justice ruled against the Irish government. Following the completion of a funding arrangement with Berkshire Hathaway, Vhi was authorized by the Central Bank of Ireland in July 2015.

Under the Voluntary Health Insurance (Amendment) Act passed in 2008, Vhi Healthcare was required to set up subsidiary companies to 
undertake non-health insurance business - another source of controversy relating to its statutory status. Previously it had been able to diversify into other business areas, with the permission of the Minister for Health and Children, without having to establish subsidiary companies (unlike its competitors), and had begun selling travel and dental insurance, set up an online health shop and become involved in minor injury clinics. The 2008 Act imposed the same subsidiary requirement on Vhi Healthcare.

\section{Risk equalization}

The main source of controversy in the market has been risk equalization. Although a risk equalization scheme was in place when it entered the market, BUPA Ireland was always opposed to the scheme on the basis that it would, in its view, be forced to subsidize the state-backed dominant insurer. Monetary transfers under the 1996 scheme were never made and the regulations governing the scheme were revoked in 1999 as part of a review of the market.

The Health Insurance (Amendment) Act, 2001 made provision for another risk equalization scheme and this was introduced as the Risk Equalization Scheme, 2003. Under the scheme, the HIA had a role in advising the Minister for Health and Children on whether or not to commence risk equalization payments. This depended on the market equalization percentage, which is an indicator of the risk differential between insurers in the market measured by the proportion of equalized benefits that insurers would be liable to pay to the risk equalization fund in order to ensure that their risk profile matched that of the market overall. If market equalization percentage was below $2 \%$, no transfers would be made. If it was between $2 \%$ and $10 \%$, the HIA would be required to make a recommendation to the Minister on whether or not payments should be triggered, while if it were above $10 \%$ then the Minister would commence payments, unless, having consulted with the HIA the Minister felt that the commencement of risk equalization payments would not be in the best overall interests of health insurance consumers (see HIA, 2003b and 2008b for further details).

For each of the 6-monthly periods from July 2003 to June 2005, the market equalization percentage was found to lie between $2 \%$ and $10 \%$ (see HIA, 2005b). For the third of these periods, the HIA recommended that payments should be commenced. However, having reviewed representations from the insurers (as allowed for under legislation), 
the Minister decided not to commence payments, noting that such a move would be premature in advance of a government decision on the commercial status of Vhi Healthcare. For the fourth of these periods, the HIA again recommended that payments should be commenced. This time the Minister decided to commence payments from 1 January 2006, as by then the government had approved legislation regarding the commercial status of Vhi Healthcare. ${ }^{27}$

As soon as payments under the scheme were triggered, BUPA Ireland challenged the scheme through the Irish courts. It had already complained to the EC that the scheme constituted illegal state aid, but the EC ruled that this was not the case in 2003 (European Commission, 2003). BUPA Ireland then took the EC to the European Court of First Instance, but in 2008 this Court dismissed BUPA Ireland's challenge to the EC's decision (European Court of Justice, 2008: p.25). A national High Court ruling in November 2006 (Courts Service, 2006) also dismissed BUPA Ireland's challenge, but BUPA Ireland appealed to the Supreme Court. Following the High Court judgement, BUPA Ireland announced that it was withdrawing from the market and its business was taken over and re-branded as Quinn Healthcare in April 2007. In July 2008, the Supreme Court overturned the High Court decision and set aside the Risk Equalization Scheme, 2003 (Courts Service, 2008). Its decision was taken on the basis of the definition of community rating in the 1994 Act, as amended. The decision did not, however, question the validity of, or need for, risk equalization in a community-rated health insurance market.

Section 7 of the 1994 Act, as amended, specifies that insurers may not vary premiums or benefits among people on the same health insurance contract. It goes on to state that "a health insurance contract that complies with [the conditions outlined in an earlier paragraph within that Section] shall be known as a community-rated health insurance

27 The decision of the Minister to commence risk equalization payments was based on analysis of the figures for the 1 January to 30 June 2005 period, but there was a lag between the end of the period and the Minister's decision to trigger payments, as the HIA had to analyse the returns from insurers and make its recommendations and the Minister had to allow the insurers to make representations. For the next 6 -monthly period, that is, 1 July to 31 December 2005, the market equalization percentage was also calculated as lying between $2 \%$ and $10 \%$ (see HIA, 2007). 
contract and 'community rating' shall be construed accordingly". The Risk Equalization Scheme, 2003 was brought forward under the terms of Section 12 of the 1994 Act, as amended. This Section noted that, in forming its decision on whether to recommend to the Minister for Health and Children that payments be triggered, the HIA needed to take into account "the best overall interests of health insurance consumers" and it went on to note that this "includes a reference to the need to maintain the application of community rating across the market for health insurance and to facilitate competition between undertakings".

BUPA Ireland argued that the only valid definition of community rating is that given in Section 7, which defines community rating within plans, and that therefore the Section 12 definition was essentially invalid, which would invalidate the entire scheme. The High Court noted that the definition of community rating was central to the case, but ruled that the Section 12 definition was valid. The Supreme Court agreed that the definition of community rating was central to the case, but decided that the Section 12 definition could not be construed so differently from the Section 7 definition. The Chief Justice, in the judgement, suggested that, if the Oireachtas (parliament) had wanted such a different interpretation to be given to the Section 12 definition then it would have made that clear. Therefore, it was the Supreme Court's view that Section 12 could only be interpreted as referring to the maintenance of community-rated plans across the market (or, in other words, community rating within plans). On this basis, the Court ruled that the Risk Equalization Scheme, 2003, as adopted by the Minister, "was founded on an erroneous interpretation of subsection 10(iii) in Section 12" and therefore determined that the 2003 scheme was ultra vires and should be set aside. The Health Insurance (Miscellaneous Provisions) Act, 2009 further amended the definition of community rating in the 1994 Act, reflecting the issues highlighted in the Supreme Court judgement and in line with Section 7(1) of the 1994 Act (Government of Ireland, 2009).

A stay on payments under the Risk Equalization Scheme, 2003 had been put in place subject to the outcome of the legal challenge. By early 2008, before the Supreme Court set aside the scheme, BUPA Ireland would have been liable to pay over $€ 33$ million into the risk equalization fund, and Quinn Healthcare would have been liable to pay just over $€ 1$ million, while Vhi Healthcare was set to receive over $€ 32$ million from the fund, with over $€ 2$ million being due to the Electricity Supply Board 
Staff Medical Provident Fund, the only one of the restricted membership undertakings participating in the scheme..$^{28,29}$

Following the setting aside of the Risk Equalization Scheme, 2003 by the Supreme Court, the Minister for Health and Children announced two interim measures which were initially put in place for 3 years (2009-2011), but were extended for another year to 2012, while work was carried out on a new risk equalization scheme. These comprised a community rating levy on health insurers for each person they insured and increased tax relief for older health insurance consumers. All insured people continued to benefit from the $20 \%$ tax relief at source, but older consumers received additional tax relief. The measures were designed to be revenue neutral to the Exchequer. Since tax relief on health insurance premiums is deductible at source, consumers pay the net premiums (net of the tax relief), and the insurers then claim back the tax relief for all of their members from the Revenue Commissioners. The additional tax relief was therefore claimed back by the insurers.

A new risk equalization scheme was introduced on 1 January 2013 and has been in operation since then with relatively little controversy compared with previous proposed risk equalization schemes. The scheme pays credits to insurers for older members, increasing by age band and differentiated by gender and level of cover (advanced or non-advanced). Risk adjusters are included in the form of credits for inpatient nights and day-case admissions. This scheme is funded by stamp duty on premiums, which vary for adults and children and also by the level of cover (advanced or non-advanced) offered on the plan. However, research has suggested that this scheme does not fully compensate insurers for cost differentials and therefore incentives remain for risk selection (Keegan et al., 2017).

The considerable controversy generated in the Irish private health insurance market stems from the market's origins, which saw the establishment of a state-backed non-profit monopoly provider that was not subject to the same prudential regulation as other financial services organizations. This arrangement survived until the passing

28 These figures relate to the periods January-June 2006, July-December 2006 and January-June 2007. For details see HIA (2008a).

29 When the Risk Equalization Scheme, 2003 was brought forward, the restricted membership undertakings were given an opportunity to opt out of the scheme. Electricity Supply Board Staff Medical Provident Fund was the only one that did not avail itself of this option. 
of the European Third Non-Life Insurance Directive in 1992, which obliged the market to open up to competition. To ensure that competition did not adversely affect the principles on which the market was then operating, these principles were given legislative foundation under the Health Insurance Act, 1994 and associated regulations. One of the main principles, community rating, was underpinned by a risk equalization scheme, which was opposed by new entrants to the market, but had cross-party political support. As part of attempts to stabilize the private health insurance market following a contraction due to the economic downturn, lifetime community rating was introduced from 1 May 2015. Attempts by the Government in power from 2011 to 2016 to introduce universal health insurance have been halted but as noted earlier, work is underway to design a single-tier health system where access is based on need rather than ability to pay.

\section{Impact of the private health insurance market on the Irish health system}

Private health insurance affects a number of health policy goals in the Irish system. In the context of the complexities that characterize the system, identifying the influence of private health insurance on equity and other goals requires more detailed and multi-dimensional analysis than has been applied in other systems.

\section{Equity and related issues}

Equity is a central goal in Irish health policy (DoHC, 2001; Department of the Taoiseach, 2011; DOH, 2012). Despite the complexities in defining equity and interpreting the goals of Irish policy statements on equity (see Smith \& Normand, 2011) it is possible to identify commitment to a general egalitarian objective in which there is a separation between payment for and use of health services.

Studies on equity in the Irish context have focused on socioeconomicrelated equity in health outcomes (Layte et al., 2015), health care utilization (Layte \& Nolan, 2004) and health care financing (Smith \& Normand, 2009; Smith, 2010a). Much of the analysis of equity in health care financing has examined measures of progressivity in health care payments. Analysis of private health insurance premium payments in Ireland using data from 1999-2000 and 2004-2005 found a regressive 
pattern, with premium payments falling as a proportion of income as income rises within the privately insured population (Smith, 2010a). This is consistent with community rating in the market, with flat rate, community-rated premiums imposing a relatively greater burden on those with relatively lower incomes. This regressive pattern could also be attributed to the purchase by lower-income, and possibly less healthy, people of more expensive (and comprehensive) insurance packages.

However, relying on progressivity indices to analyse equity in health care financing overlooks complexities that need to be taken into account when considering the impact of private health insurance on equity (Smith \& Normand, 2009). First, payment for private health insurance includes not just premium payments made by individuals (or their employers) but also public resources in the form of tax relief on premiums (described earlier). Tax relief might be expected to increase demand for health insurance. However, its impact seems to have been relatively limited given the strong growth in demand for private health insurance over time in spite of reductions in the level of tax relief (for example, from marginal to standard tax rate in $1995,{ }^{30}$ and the more recent cap on the premium on which tax relief is available). Nevertheless, it is a substantial subsidy on the cost of private health insurance and there have been repeated calls for its abolition (see, for example, Commission on Health Funding, 1989; Ruane, 2010).

Second, the state also subsidizes the private health insurance market indirectly via the provision of education and training for medical professionals. Some of the treatment of privately insured individuals takes place in public hospitals, and some hospital consultants work in both public and private practice, so the training of these medical professionals, which is subsidized by the state, benefits both public and private patients.

Third, when analysing equity in private sources of health care financing it is important to consider what is happening in health care delivery. Private spending is directly linked to use of or entitlement to services (see Smith \& Normand, 2009). In the Irish case, purchase of private health insurance can bring with it entitlements and patterns of health care use that have negative equity implications within the health sector. In particular, analysis of health care financing and delivery

${ }^{30}$ Motivated by concerns to improve the progressivity of the relief since relief granted at the marginal tax rate disproportionately benefited those on higher incomes who paid tax at a higher marginal rate. 
together shows that public subsidization of privately insured care is not necessarily limited to tax relief on insurance premiums and training of medical professionals.

In practice, a proportion of privately insured care is delivered in public hospitals. ${ }^{31}$ Charges for privately insured care ${ }^{32}$ in public hospitals do not cover the full economic cost of that care, leading to additional subsidies. Identifying the full economic cost is not straightforward and analysis in this area has been ongoing (Brick et al., 2010). Earlier estimates indicated that the level of subsidization could be as high as $50-60 \%$ of the cost of privately insured care (Nolan \& Wiley, 2000; Smith, 2008). More recent evidence is not available and would need to take into account the impact of levying private bed charges on all beds occupied by privately insured patients in public hospitals from 1 January, 2014.

In addition to the subsidization of private care in public hospitals, there are concerns about two-tier access to care within the public hospital system, with privately insured patients receiving priority over, and crowding out, public patients. Before the changes to the common consultant contract in 2008, public hospitals were required to implement a bed designation system intended to safeguard the access of publicly financed patients to public hospital care. Approximately $20 \%$ of inpatient non-emergency hospital beds were designated for private patients, with the rest nominally restricted to public patients. However, data on inpatient admissions and discharges indicated that this system was violated and private practice exceeded permitted levels in some hospitals (Wiley, 2001; Brick et al., 2010). The increase in day-case

31 Published data on the proportion of privately insured care that takes place in public hospitals are limited. The 2003 Vhi annual report indicated that $50 \%$ of bed capacity used by its members was provided in public hospitals (Vhi, 2003). The 2009 Vhi report forecast that $70 \%$ of the members' health care needs in 2010 would be delivered in private hospitals/facilities (Vhi, 2009). These two measures, although not fully consistent, indicate that a large proportion of privately insured care is delivered in public hospitals but that this has been declining over time. Available survey data on health care utilization indicates that $60 \%$ of adults with private health insurance who were admitted as inpatients over a 12 -month period were admitted to public hospitals, compared with $90 \%$ of those with medical cards and $97 \%$ of those with neither form of cover (CSO, 2011).

${ }^{32}$ It is possible to receive private care without holding private health insurance but this is expected to refer to a small proportion of the population. 
activity in public hospitals further confused the situation and internal reports by the Department of Health and Children acknowledged that the bed designation system had not succeeded in controlling the level of private activity within public hospitals (Tussing \& Wren, 2006). On the demand side, as noted earlier, available data indicate that greater access to hospital care and other non-financial factors have been cited as key reasons for purchasing private health insurance in Ireland.

Moreover, the two-tiered nature of the Irish health care system has been explicitly acknowledged in a number of recent health policy documents. The White Paper on Universal Health Insurance cites the Government's commitment to "ending the unfair, unequal and inefficient two-tier health system" (DOH, 2014: p.5) while the Strategic Framework for Reform of the Health Service outlines the proposed steps to achieve a "single-tier health service" (DOH, 2012: p.1). Concerns about two-tier access and quality are not new. The Commission on Health Funding (1989) recommended the introduction of a common waiting list for public hospital admission, such that cases would be taken in order of medical priority regardless of public/private status (Nolan \& Wiley, 2000). Measures to restrict the number of private patients treated within the public hospital system also feature in the revised 2008 consultant contract. For newly appointed Type B consultants, the permitted ratio of public to private workload is $80: 20$. The new consultant contract contains improved measures for monitoring agreed levels of public and private activity relative to the previous contract. However, it is not clear to what extent the revised working arrangements are being adhered to or sanctioned. ${ }^{33}$

These patterns illustrate how the level of resources generated by private health insurance is not commensurate with the leverage within the health system enjoyed by those with private cover (Nolan, 2006). Observed negative repercussions include long waiting times for publicly financed patients. Waiting times have been central to political and policy debates in the health sector, with particular focus on the large gap in

${ }^{33}$ Limited available evidence indicates that the agreed levels of public and private activity for those on a Type B consultant contract are not being adhered to (Brick et al., 2010; The Irish Times, 2016, www.irishtimes.com/news/health/ rules-limiting-private-practice-in-hospitals-a-farce-hse-chief-1.2490156 last accessed 29/11/2016). 
waiting times between public and private patients (Tussing \& Wren, 2006). The most recent health policy documents directly acknowledge the challenges of "long waiting lists and inequitable access to care" (DOH, 2012: p.2) and various waiting list initiatives have been introduced by the government over the years. ${ }^{34}$

Previous analysis of health care financing and delivery structures in Ireland have identified complicated and inequitable flows of resources through the system (Smith \& Normand, 2009) and many of these inequitable structures persist. The purchase of private health insurance is subsidized, via tax relief on premiums, by all individuals in the tax net. As outlined earlier, private health insurance is concentrated among higher-income groups in the population. There is no clear equity principle that would allow lower-income groups to subsidize the purchase of private insurance by higher-income groups, which would subsequently allow those higher-income groups preferential access to a bed in a public hospital, yet this is observed in the Irish system. ${ }^{35}$

${ }^{34}$ In 2002, the National Treatment Purchase Fund (NTPF) was established to purchase private care (in Ireland and abroad) on behalf of public patients waiting extended periods of time for care. As a result, the problem of long public waiting times led to further demands on public resources. While the NTPF was successful in reducing waiting lists (Ruane, 2010), it gave rise to a complex flow of resources in the system. In 2011, the NTPF was subsumed into the Special Delivery Unit, and its role in arranging private treatment for patients was suspended. However, funds were made available in Budget 2017 (announced in October 2016) for the NTPF to again arrange treatment in an effort to reduce waiting lists.

35 The National Treatment Purchase Fund (NTPF) set up another pattern of potentially inequitable cross-subsidization effects. Public resources (generated by all tax payers) were used to purchase private care for public patients (via the NTPF) at the same time as there was evidence that public resources were used to subsidize the treatment of private patients within public hospitals. This anomaly was taken up by the Expert Group on Resource Allocation and Financing in the Health Sector in 2010 (Ruane, 2010). The Group recommended that when appropriate measures are taken to improve resource allocation in the system (for example, treatment protocols and frameworks, a prospective funding mechanism), there would no longer be a need for the NTPF to continue its role in relation to purchasing services to reduce waiting lists, as this role will be mainstreamed into the rest of the system (Ruane, 2010). 


\section{Incentives and policy responses}

Supply-side financial incentive structures in acute care ${ }^{36}$ also support the leverage of private health insurance within the system, with implications for the behaviour of hospital consultants, hospital managers and insurers. As noted earlier, hospital consultants permitted to treat both public and private patients may have a financial incentive to treat private patients. ${ }^{37}$

Acute public hospitals receive income from statutory public inpatient charges (€75 per day) and from maintenance charges for private patients treated in public hospitals (€659 to $€ 1000$ per night and from $€ 329$ to $€ 407$ for day cases, depending on the type of hospital) (Turner, 2015). The private maintenance charge is payable in addition to the public hospital inpatient bed charge. Thus, public hospitals have an incentive to ensure that their private beds are filled to maximum capacity by private patients (private maintenance charges are not recouped where private beds are occupied by public patients) and an incentive to earn additional income by filling public beds with private patients. ${ }^{38}$.

Insurers cover the costs of hospital maintenance and consultant treatment for care provided to privately insured patients. In previous years, charges for treatment were generally higher in private than in public hospitals (Brick et al., 2010), particularly where a private patient was treated in a public bed in a public hospital. ${ }^{39}$ Policy decisions to increase the private and semi-private bed charges in public hospitals over time [for example, between 2005 and 2013, private and semi-private

${ }^{36}$ See Brick et al. (2012) for further discussion of incentives in acute care services.

${ }^{37}$ Fee-for-service payments are directly tied to the amount of services provided and therefore encourage greater activity relative to salary-based payment mechanisms. However, there are other complicating factors also at play, which may conflict with the incentive to favour the treatment of private patients, outlined in more detail by Brick et al. (2012).

${ }^{38}$ Once a private patient is admitted, the public hospital has a financial incentive to maximize length of stay but to minimize treatment intensity because the per diem payment is independent of the type of treatment received. In contrast, the Type B consultant may have a financial incentive to increase treatment intensity, which could increase his/her income (Brick et al., 2012).

39 One review of public hospital accounts showed that $45 \%$ of private patients were not charged for maintenance because they occupied a public bed (see Brick et al., 2010), whereas around $5 \%$ were treated in non-designated beds (Comptroller and Auditor General, 2009). 
maintenance charges for large acute public hospitals increased by more than $200 \%$ (Turner, 2015)], and to charge private rates for any bed occupied by private patients in public hospitals (since 1 January, 2014) reduce the incentive facing the insurer to favour the treatment of private patients within public rather than private hospitals.

However, focusing on one incentive without addressing others can have limited impact on actual behaviour. Consultants are directly paid by insurers for care delivered to privately insured patients. With regard to decisions on treating private patients in public or private hospitals it is interesting to note that the consultants receive those resources regardless of where the care is provided. For convenience, consultants might prefer to conduct most of their private and public work from one location. From the perspective of an individual public hospital, privately insured patients provide a source of income. ${ }^{40}$ The influence of these incentives persists despite the changes to the structure of private maintenance charges.

Overall, the structure of the Irish health financing system is complex and the role of private health insurance within that system is no less complicated. Despite accounting for a relatively small proportion of total health care resources, private health insurance has important leverage on how resources in the public hospital system are allocated, giving rise to complicated incentive structures and inequitable patterns of access and use of services within the system.

\section{Quality and efficiency}

The way in which privately insured care interacts with the public system has negative implications for the efficiency with which public resources are used in the system and for the quality of care received by public patients. With regard to the care received by privately insured patients, there is limited evidence that private insurers actively implement disease management initiatives in the Irish context or take other steps to promote efficiency. ${ }^{41}$ They do not set treatment protocols or

40 Treatment of privately insured patients in a public hospital also means that consultants are more likely to be on site and are therefore potentially more available to treat public patients.

${ }^{41}$ Earlier commentary indicated that private insurers negotiated contracts with health care providers to contain costs rather than to promote specific health practices (Colombo \& Tapay, 2004). 
medical guidelines to increase the appropriateness of care or efficiency of resource allocation. However, some insurers are becoming more involved in health-promoting activities (for example, sponsoring health-related events, electronic newsletters, etc., and Vhi Healthcare has begun a screening programme for diabetes), which may be related to the growth in insurance products that cover primary care services.

\section{Administrative efficiency}

Operating expenses of Vhi Healthcare accounted for $7.7 \%$ of gross earned premium in 2014, having been just over $6 \%$ in four previous years (Vhi, 2015). In the period following the opening of the market to competition, the administrative cost percentage steadily increased to reach a peak of more than $11 \%$ in 2001, but after that the rate declined (Colombo \& Tapay, 2004; Vhi, 2007, 2008). Vhi Healthcare cites investment in the development of appropriate information technology as an important contributing factor to operational efficiency (Vhi, 2008).

\section{Financial protection}

As outlined earlier, avoiding large hospital bills is one of the reasons, but not the main reason, cited for purchasing private health insurance. Financial protection may have been a more important factor when private health insurance was first introduced and targeted at individuals who at the time were not entitled to free care in public hospitals. Even then, these individuals were among the top $15 \%$ of earners in the population and their risk of falling into poverty as a result of medical bills is assumed to have been low. Fig. 7.2 shows the financial mix of health care resources allocated to four different entitlement groups based on data from 2004 (Smith \& Normand, 2009). The entitlement groups (outlined earlier) are broadly ranked in increasing order of socioeconomic/health status. Most of the health care services received by the group with a Medical Card only are financed from public sources, while private sources play a more important role in the financing of health care services for the other three groups. The group without cover from a Medical Card or private health insurance relies to a relatively large extent on out-of-pocket payments to supplement public resources. The group with private health insurance only can offset some of the out-ofpocket payments (that is, hospital charges) that face non-medical card 


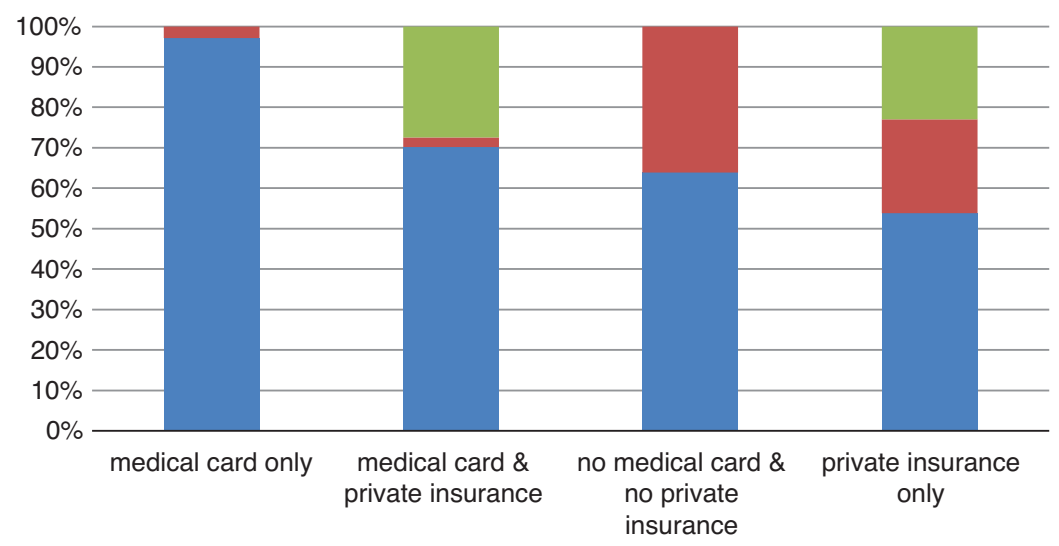

public resources out-of-pocket resources $\square$ private health insurance

Figure 7.2 Composition of health care resource allocation for different entitlement groups in Ireland, 2004

Source: Extracted from Smith \& Normand (2009).

holders in the system. However, while out-of-pocket payments make up a smaller proportion of total resources allocated to the group with private health insurance relative to the group with no cover, they do not disappear completely. This is because the former group still has to pay out of pocket for primary care. The limited financial protection by the state for primary care for the non-medical card groups is a distinguishing feature of the Irish health system (Smith, 2010b; Burke et al., 2015). Further work is needed to incorporate changes in eligibility and financing structures since then (for example, GP Visit Cards, increasing cover of primary care by private health insurance companies). Nevertheless the general health care financing structure underpinning each eligibility group still holds (for example, Medical Card holders: mainly public resources with a small proportion of out-of-pocket financing for prescription charges; Privately insured: mainly private health insurance for acute care and out-of-pocket payments for primary care; No Medical Card or private health insurance: mainly out-of-pocket payments).

\section{The future of private health insurance in Ireland}

Given the complicated interaction between privately insured care and the rest of the health system, future developments around private health 
insurance are difficult to predict. Changes in the private health insurance market can occur in terms of the size and structure of the market, and the interaction with and the impact on the wider health system. Each of these is affected by a wide range of factors, as evidenced by the recent economic downturn.

With regard to the structure of the private health insurance market, the introduction of risk equalization from January 2013 has brought an end to the long-running uncertainty surrounding this measure, although as noted earlier, it has not entirely eliminated the incentives for risk selection and some possible changes have been suggested (Keegan et al., 2017).

The recent entry of general insurers into the market for private health insurance, and the normalization of Vhi Healthcare as an authorized non-life insurer in 2015, may lead to bundling of private health insurance with other forms of insurance. In past years, the Quinn Group (before the buyout that led to Quinn Healthcare becoming Laya Healthcare) offered free household insurance to the value of $€ 200$ and free travel insurance to customers holding motor and health insurance with the Quinn Group (Quinn Healthcare, 2008). Hibernian AVIVA Health also ran a "match more, make more" promotion, offering cash back to customers who had multiple policies with the group, including health and motor insurance. There is currently some degree of product bundling between private health insurance and travel insurance, with Vhi Healthcare's travel insurance plan paying for medical care while on holiday only after the limit on the overseas-cover element of the insured person's private health insurance plan has been exceeded. As the market for private health insurance is possibly close to saturation (although HIA, 2016a showed that $38 \%$ of those who did not already have private health insurance said they were likely to take it out at some point in the future), diversification into other insurance - and non-insurance - areas may be a logical step for insurers.

Further increases in private health insurance premiums, in both nominal and real terms, are also likely to feature in the future. Factors affecting these increases will include the ageing population, advances in medical technology and possible increases in bed charges for privately insured patients in public hospitals, which are set unilaterally by the Minister for Health. Expansion in the supply of public facilities could also dampen demand for private health insurance, although given restricted budgets it is questionable whether this will happen to any 
great extent in the short- to medium-term. Consumer surveys (HIA, 2003a, 2005a, 2008c, 2010a) have shown a general satisfaction with health insurance, but the level of agreement that it represents value for money decreased during the economic downturn (HIA, 2016a), although the market has now seen a modest increase in demand again, even after the once-off effect of the introduction of lifetime community rating. The fact that the market contracted by only $12 \%$ from peak to trough, despite like-for-like premium increases of over $120 \%$ during the same period, suggests significant resilience in demand for health insurance in Ireland.

In terms of the wider implications of private health insurance on health equity and efficiency goals, the recent adjustments to tax relief on premiums, and the equity implications of the lifetime community rating and risk equalization, outlined earlier, will need to be assessed. It is also important to note that without further changes to the incentive structures that favour the treatment of private patients in the public health system, and without full enforcement of the new consultant contract requirements on the ratio of public/private activity, private health insurance will continue to have a distorting effect on the allocation of health care resources within the public hospital system. Any decline in demand for private insurance induced by price rises or improvements in the public health system will not remove these inequitable distortions, but it may make them less visible.

It is also important to look at the future of private health insurance in the broader policy context of health care financing and delivery in Ireland. Much of the discussion in recent years has focused on options for changing the financing mechanism for health care. The Adelaide Hospital Society investigated options for a contributions-based "social health insurance" system to replace the current government-budget-financed system (Thomas, Normand \& Smith, 2008). However, a shift to a contributions-based system is not a necessary condition for achieving improvements in resource allocation and equity in the Irish health system. Many of the desirable features identified with a contributionsbased system (for example, potential improvements in transparency, a greater degree of prepayment in the system and increasing incentives to provide services efficiently and in the appropriate locations) can be achieved under the current system (Ruane, 2010).

Subsequently, the Programme for Government issued by the coalition government elected in 2011 (Department of the Taoiseach, 2011) 
outlined a plan to introduce a system of universal health insurance involving mandatory coverage of the whole population provided by competing private insurers, which could selectively contract with providers. Under these proposals, the State would pay for cover on behalf of those on low incomes and partially subsidize the cost for those on middle incomes, whereas those on higher incomes would pay the full cost. Under the plans, voluntary health insurance would no longer be able to offer faster access to hospital care, but may still be able to provide better amenities in hospital. A primary objective was to tackle unequal access to hospital care. The White Paper on universal health insurance was published in April 2014 (DoHC, 2014) and the consultation process that followed demonstrated considerable concerns about the proposed model (Crowe Horwath, 2014). These included concerns in relation to cost and cost containment, and the ability of individuals - particularly those who currently do not have voluntary health insurance or a Medical Card - to pay for mandatory health insurance (Turner, 2014) and the ability of insurers to engage in selective contracting, given the relatively low density of facilities in many parts of the country (Mikkers \& Ryan, 2014).

More recently, following a review of the potential costs of universal health insurance (Wren, Connolly \& Cunningham, 2015), the proposals in that reform were effectively shelved. A recent report noted a number of challenges in achieving universal health care, and explored some potential routes to advancing towards universality (for example, extension of tax-financed primary care system; addressing two-tier access to hospital care by introducing a new public purchaser of hospital care, or some modified model of compulsory private insurance for elective hospital care only) (Wren \& Connolly, 2016).

The Committee on the Future of Healthcare was established in June 2016 with the task of developing a consensus-driven 10-year plan for health policy in Ireland. The Committee has appraised various funding model options for moving to a universal single-tier system, and considered a number of options when looking at what the position of private health insurance would be in this system. Its plan (Sláintecare Report), published in May 2017, recommends a model where private insurance will no longer confer faster access to health care in the public sector, but is limited to covering private care in private hospitals (private care in public hospitals will be eliminated) (Houses of the Oireachtais, 2017). 


\section{Concluding comments}

This chapter has shown how the development and functioning of the private health insurance market in Ireland has been complicated and controversial. One of the most complex issues concerns the role of privately insured care within the health system. Although private health insurance accounts for a relatively small proportion of total health care financing, it has substantial leverage in terms of how resources are allocated, particularly for acute care. A key reason behind strong demand for private health insurance is to ensure faster access to hospital care, very often in a public hospital. This close interaction between publicly and privately financed care is key to understanding the impact private health insurance has on equity and efficiency in the Irish health system.

\section{References}

Altman D, Cutler D, Zeckhauser R (1998). Adverse selection and adverse retention. Papers and Proceedings of the Hundred and Tenth Annual Meeting of the American Economic Association (May). American Economic Review, 88(2):122-6.

Brick A et al. (2010). Resource allocation, financing and sustainability in health care: evidence for the Expert Group on Resource Allocation and Financing in the Health Sector. Dublin, Department of Health and Children and Economic and Social Research Institute.

Brick A et al. (2012). Conflicting financial incentives in the Irish health-care system. The Economic and Social Review, 43(2):273-301.

Burke $S$ et al. (2015). From universal health insurance to universal healthcare? The shifting health policy landscape in Ireland since the economic crisis. Health Policy, 120(3):235-40.

Citizens Information (2015a). Entitlement to health services: www.citizens information.ie/en/health/entitlement_to_health_services/entitlement_to_ public_health_services.html; accessed on 17/12/2015.

Citizens Information (2015b). Community care services: www.citizens information.ie/en/health/care_in_your_community/community_care_ services.html; accessed on 17/12/2015.

Colombo F, Tapay N (2004). Private health insurance in Ireland: a case study. OECD Health Working Paper 10. Paris, OECD. 
Commission on Health Funding (1989). Report of the Commission on Health Funding. Dublin, Stationery Office.

Competition Authority (2007). Competition in the Irish private health insurance market. Dublin, The Competition Authority.

Comptroller and Auditor General (2009). Accounts of the Public Services 2008: Comptroller and Auditor General Annual Report. Dublin, Office of the Comptroller and Auditor General.

Courts Service (2006). Case IEHC 431. BUPA Ireland Ltd \& Anor v. Health Insurance Authority \& Ors. Dublin, Courts Service.

Courts Service (2008). Case IESC 42. BUPA Ireland Ltd \& Anor v. Health Insurance Authority \& Ors. Dublin, Courts Service.

Crowe Horwath (2014). Final Report to Department of Health: Thematic Analysis of Submissions in Response to a Public Consultation on the White Paper for Universal Health Insurance. Dublin, Department of Health.

CSO (2011). Health status and health service utilisation: quarterly national household survey. Quarter 3 2010. Dublin, Central Statistics Office.

Department of the Taoiseach (2011). Programme for Government 2011: www.taoiseach.gov.ie/eng/Publications/Publications_2011/Programme_ for_Government_2011.pdf; accessed on 31/08/2011.

DOH (2012). Future Health. A Strategic Framework for Reform of the Health Service 2012-2015. Dublin, Department of Health: http://health.gov.ie/ blog/publications/future-health-a-strategic-framework-for-reform-of-thehealth-service-2012-2015/; accessed on 20/11/2015.

DOH (2014). The Path to Universal Healthcare. White Paper on Universal Health Insurance. Dublin: Department of Health: http://health.gov.ie/ future-health/universal-health-insurance/the-white-paper-on-uhi/; accessed on $22 / 11 / 2015$.

DoHC (1999). Private health insurance. White Paper. Dublin, Stationery Office.

DoHC (2001). Quality and fairness for all. A health system for you. Dublin, Stationery Office.

DoHC (2005). Taxation and medical expenses. Dublin, Department of Health and Children: www.dohc.ie/public/information/taxation_and_medical_ expenses.html; accessed on 24/03/2005.

DoHC (2014). The Path to Universal Healthcare: White Paper on Universal Health Insurance. Dublin, Department of Health and Children.

European Commission (2003). State Aid N46/2003 - Ireland. Risk equalisation scheme in the Irish health insurance market. Brussels, European Commission, Directorate General for Competition. 
European Court of Justice (2008). Case T-289/03. British United Provident Association Limited (BUPA) and Others v. Commission of European Communities. Luxemburg, European Court of Justice.

Expert Panel on Medical Need for Medical Card Eligibility (2014). Report of the Expert Panel on Medical Need for Medical Card Eligibility. Dublin: Health Service Executive: www.hse.ie/eng/services/publications/corporate/ expertpanelmedicalneed.pdf; accessed on 24/11/2015.

Government of Ireland (2001). Health (Miscellaneous Provisions) Act 2001: www.irishstatutebook.ie/pdf/2001/en.act.2001.0014.pdf; accessed on 26/08/2011.

Government of Ireland (2008). Health Act 2008: www.irishstatutebook .ie/2008/en/act/pub/0021/index.html; accessed on 26/08/2011.

Government of Ireland (2009). Health Insurance (Miscellaneous Provisions) Act 2009: www.irishstatutebook.ie/2009/en/act/pub/0024/index.html; accessed on 12/09/2011.

Government of Ireland (2014). Statement of Government Priorities 20142016: www.taoiseach.gov.ie/eng/Publications/Publications_2014/Statementof-Government-Priorities-2014-2016.pdf; accessed on 17/12/2015.

Harmon C, Nolan B (2001). Health insurance and health services utilization in Ireland. Health Economics, 10(2):135-45.

Health Information and Quality Authority (2014). Annual overview report on the regulation of designated centres for older people - 2013. Dublin, Health Information and Quality Authority: www.hiqa.ie/publications/ annual-overview-report-regulation-designated-centres-older-people$\%$ E2\%80\%93-2013-0; accessed on 16/12/2015.

HIA (The Health Insurance Authority) (2003a). The private health insurance market in Ireland. Report prepared by Amárach Consulting for the Health Insurance Authority, March 2003. Dublin, The Health Insurance Authority. HIA (2003b). Risk equalisation: guide to the Risk Equalisation Scheme, 2003 as prescribed in Statutory Instrument No. 261 of 2003. Dublin, The Health Insurance Authority.

HIA (2005a). The private health insurance market in Ireland: a market review. Report prepared by Insight Statistical Consulting for the Health Insurance Authority, September 2005. Dublin, The Health Insurance Authority.

HIA (2005b). Staff report to the members of the Health Insurance Authority in relation to its statutory functions and duties regarding risk equalisation. Dublin, The Health Insurance Authority.

HIA (2007). Competition in the Irish private health insurance market: A report to the Minister for Health and Children. Dublin, The Health Insurance Authority. 
HIA (2008a). Summary of amounts due under Risk Equalisation Scheme. Dublin: The Health Insurance Authority: www.hia.ie/assets/files/ publications/Risk_Equalisation/Payments-due-under-the-RE-Scheme.pdf; accessed on $7 / 08 / 2008$.

HIA (2008b). Risk equalisation: updated guide to the Risk Equalisation Scheme, 2003 as prescribed in Statutory Instruments No. 261 of 2003, No. 710 of 2003, No. 334 of 2005 and No. 220 of 2007. Dublin, The Health Insurance Authority.

HIA (2008c). The private health insurance market in Ireland: a market review. Report prepared by Insight Statistical Consulting, March 2008. Dublin, The Health Insurance Authority.

HIA (2010a). The private health insurance market in Ireland. Report prepared by Red C Research \& Marketing Limited, May. Dublin, The Health Insurance Authority.

HIA (2010b). Annual report and accounts 2009. Dublin, The Health Insurance Authority.

HIA (2012). Report on the Health Insurance Market. Report prepared by Millward Brown Landsdowne. Dublin, The Health Insurance Authority. HIA (2014). Report on the Health Insurance Market. Report prepared by Millward Brown. Dublin, The Health Insurance Authority.

HIA (2016a). A review of private health insurance in Ireland. Report by Millward Brown. Dublin, The Health Insurance Authority.

HIA (2016b). Annual report and accounts 2015. Dublin, The Health Insurance Authority.

HIA (2016c). Market statistics 2015. Dublin, The Health Insurance Authority. HIA (2016d). Newsletter, August 2016 edition. Dublin, The Health Insurance Authority.

Houses of the Oireachtas (2017). Committee on the Future of Healthcare Sláintecare Report. Dublin, Houses of the Oireachtas, May 2017.

HSE (Health Service Executive) (2015a). Your guide to medical cards: www .hse.ie/eng/services/list/1/schemes/mc/focuson/aboutmedicalcards. 205700 .shortcut.html; accessed on 17/12/2015.

HSE (2015b). Medical Card/G.P. Visit card national assessment guidelines. Dublin, Health Service Executive: www.hse.ie/eng/services/list/1/schemes/ mc/forms/medicalcardguidelines2015.pdf; accessed on 26/11/2015.

HSE (2015c). Medical workforce planning. Future demand for general practitioners 2015-2025. Dublin, National Doctor Training and Planning, HR Directorate, Health Service Executive: www.hse.ie/ portal/eng/staff/Leadership_Education_Development/MET/plan/ 
reports/Medical_Workforce_Planning_Future_Demand_for_General_ Practitioners_2015-2025.pdf; accessed on 26/11/2015.

HSE (2015d). Public hospitals in Ireland. Dublin, Health Service Executive: www.hse.ie/eng/services/list/3/hospitals/; accessed on 22/11/2015.

HSE (2016). Annual report and financial statements 2015. Naas, Health Service Executive.

Keegan C et al. (2016). Switching insurer in the Irish voluntary health insurance market: determinants, incentives, and risk equalization. European Journal of Health Economics, 17(7):823-31.

Keegan C et al. (2017). Addressing market segmentation and incentives for risk selection: How well does risk equalisation in the Irish private health insurance market work? The Economic and Social Review, 48 (1): 61-84.

Layte R, Nolan B (2004). Equity in the utilisation of health care in Ireland. The Economic and Social Review, 35(2):111-34.

Layte $\mathrm{R}$ et al. (2015). Trends in socio-economic inequalities in mortality by sex in Ireland from the 1980s to the 2000s. Irish Journal of Medical Science, 184(3):613-21.

Mikkers M, Ryan P (2014). “Managed Competition” for Ireland? The single versus multiple payer debate. BMC Health Services Research, 14(1):442.

Nolan A, Smith S (2012). The effect of differential eligibility for free GP services on GP utilisation in Ireland. Social Science and Medicine, 74(10):1644-51.

Nolan B (2004). Health insurance in Ireland: issues and challenges. Economie Publique, 14(1):55-62.

Nolan B (2006). The interaction of public and private health insurance: Ireland as a case study. Geneva Papers on Risk and Insurance, 31(4):633-49.

Nolan B, Wiley M (2000). Private practice in Irish public hospitals. Dublin, Oak Tree Press.

O'Morain P (2007). The health of the nation: the Irish healthcare system 1957-2007. Dublin, Gill and Macmillan.

PCRS (Primary care reimbursement service) (2007). Finance shared services primary care reimbursement service: statistical analysis of claims and payments 2007. Dublin, Health Service Executive.

PCRS (2015). Primary care reimbursement service: statistical analysis of claims and payments 2015. Dublin, Health Service Executive.

Price J, Mays J (1985). Selection and the competitive standing of health plans in a multiple-choice, multiple-insurer market. In: Scheffler R, Rossiter L, eds. Advances in health economics and health services research, vol. 6. Greenwich, CT, JAI Press. 
Private Health Insurance Advisory Group (2007). A business appraisal of private medical insurance in Ireland. Report for the Minister for Health and Children. Dublin, Department of Health and Children.

Quinn Healthcare (2008). Quinn Healthcare reduces prices, introduces new schemes and benefits, and offers free travel insurance proving competition is good for your health, Press release, 27 May: www.quinnhealthcare.com/press_and_media/pressrelease280508.htm; accessed on 15/12/2016.

Ruane F (2010). Report of the Expert Group on Resource Allocation and Financing in the Health Sector. Dublin, Department of Health and Children.

Smith S (2008). Equity in Irish health care financing [thesis]. Dublin, Trinity College.

Smith S (2010a). Equity in Irish health care financing: measurement issues. Health Economics, Policy and Law, 5(2):149-69.

Smith S (2010b). The Irish 'health basket': a basket case? European Journal of Health Economics, 11(3):343-50.

Smith S, Normand C (2009). Analysing equity in health care financing: a flow of funds approach. Social Science \& Medicine, 69(3):379-86.

Smith S, Normand C (2011). Equity in health care: the Irish perspective. Health Economics, Policy and Law, 6:205-17.

Thomas S, Normand C, Smith S (2008). Social health insurance: further options for Ireland. Dublin, The Adelaide Hospital Society.

Thomson S, Mossialos E (2007). Regulating private health insurance in the European Union: the implications of single market legislation and competition policy. Journal of European Integration, 29(1):89-107.

Timonen V, Doyle M, O'Dwyer C (2012). Expanded, but not regulated: ambiguity in home-care policy in Ireland. Health and Social Care in the Community, 20(3):310-18.

Turner B (2013). Premium inflation in the Irish private health insurance market: drivers and consequences. Irish Journal of Medical Science, 182(4):545-50.

Turner B (2014). The path to universal health care: White paper, red flags. Administration, 62(3):39-61.

Turner B (2015). Unwinding the State subsidisation of private health insurance in Ireland. Health Policy, 119(10):1349-57.

Turner B (2016). The new system of health accounts in Ireland: what does it all mean? Irish Journal of Medical Science, 186(3):533-40.

Turner B, Shinnick E (2008). The development of the Irish private health insurance market and evidence of selection effects therein. Working Paper No. 08-02. Cork, University College Cork, Department of Economics. 
Tussing D, Wren M-A (2006). How Ireland cares: the case for health care reform. Dublin, New Island.

Vhi (2003). Annual report and accounts, 2003. Dublin, Voluntary Health Insurance Board.

Vhi (2007). Annual report and accounts 2007. Dublin,Voluntary Health Insurance Board.

Vhi (2008). Annual report and accounts, 2008. Dublin, Voluntary Health Insurance Board.

Vhi (2009). Annual report and accounts, 2009. Dublin, Voluntary Health Insurance Board.

Vhi (2015). Annual Report and Accounts 2014. Dublin, Voluntary Health Insurance Board.

WHO (2018). Global health expenditure database (GHED) [online database]. Geneva, WHO: www.who.int/health-accounts/ghed/en/; accessed on $15 / 01 / 2018$.

Wiley MM (2001). Reform and renewal of the Irish health care system: policy and practice. In: Callan T, McCoy D, eds. Budget perspectives: proceedings of a conference held on 9 October 2001. Dublin, ESRI.

Wren M-A, Connolly S (2016). Challenges in achieving universal healthcare in Ireland. Dublin, ESRI.

Wren M-A, Connolly S, Cunningham N (2015). An examination of the potential costs of universal health insurance in Ireland. Dublin, ESRI.

York Health Economics Consortium (2003). Assessment of risk equalisation and competition in the Irish health insurance market - final report. York, York Health Economics Consortium: www.hia.ie/sec3_reports/AppendixIII .pdf; accessed on 15/12/2016. 